\title{
Technology Forecasting for Medical Devices Guidance Formulation: A Case Study in Japan
}

Therapeutic Innovation \& Regulatory Science 2019, Vol. 53(4) 48I-489 (C) The Author(s) 2018 Article reuse guidelines: sagepub.com/journals-permissions DOI: $10.1177 / 2168479018793370$ tirs.sagepub.com

\author{
Sayaka Itoh, $\mathrm{MSc}^{\prime}{ }^{\circledR}$, and Shingo Kano, $\mathrm{PhD}^{\prime}$
}

\begin{abstract}
In the advanced medical field, there is a constant need for efficient guidance formulation by regulators. Technology forecasting as a surveillance for regulation needs may be an effective solution by notifying regulatory authorities of the possible future changes in regulations. However, the lack of tangible frameworks has made the relationship between technology forecasting and regulation difficult to comprehend, and has led to an under-analyzed state of how technology forecasts are implemented into the guidance formulation process. In this study, we introduce a framework built specifically for facilitating the comprehension of the relationship between technologies enlisted in technology forecasting and guidances formulated after the forecasting, and applied the framework to a case of technology forecasting conducted by regulatory authorities in Japan. Four patterns of the relationships between a technology forecasting conducted by regulators and the guidances developed after the forecast are identified. The results and discussions provide suggestions of technology forecast design and application in the guidance formulation process by regulators in the field of medical devices.
\end{abstract}

\section{Keywords}

technology forecasting, guidance, medical device, classification, regulation

\section{Introduction}

\section{Technology Growth and Regulatory Reform}

The rapid growth of life science technologies has prompted increases in investments in the field over the last decade, with no signs of slowing down. ${ }^{1}$ Accordingly, it is challenging to predict emerging technologies and to select and prioritize subjects that require policy and regulatory changes. ${ }^{2}$ With the intention of promoting innovation related to medicine and health, the US Food and Drug Administration (FDA) established the Critical Path Initiative (CPI) in 2004, in which they identified therapeutic fields and technologies that would provide the best chance of resolving stagnation in the development of innovative therapies and benefit public health; thus, they announced policies to undertake guidance maintenance in prioritized areas. ${ }^{3,4}$ Many regulatory changes including the formulation of guidances have also been made in recent years in the advanced medical field, and the development of appropriate guidances continues to be a priority for guidance formulators. ${ }^{5}$

\section{Technology Forecasting}

Technology forecasting (and foresights) are conducted in order to avoid ineffective or tardy national policies, regulatory activities, and corporate management strategies. ${ }^{6,7}$ Governments, global and national organizations, and enterprises must be proactive in making roadmaps or constructing reliable frameworks in order to predict future developments in the scientific world, including the medical field. For example, the National Institute of Science and Technology Policy (NISTEP) in Japan has delivered Delphi surveys every 5 years since 1971 in order to identify future technologies expected to be developed in the next 30 years. ${ }^{8,9}$ Although the results of NISTEP's forecasts may provide essential consultative information for guidance formulation, they do not aim to facilitate guidance formulation in a specific field.

There have been debates over the importance of identifying emerging and new technologies in the policy process. For example, Wild and Langer argued that identification, prioritization, and early assessment of emerging technologies are the first 3 important steps to successfully inform and support health policy at an early stage. ${ }^{10}$ However, no studies have analyzed

\footnotetext{
'Bio-Innovation Policy Unit, Department of Computational Biology and Medical Sciences, Graduate School of Frontier Sciences, the University of Tokyo, Kashiwa City, Chiba, Japan
}

Submitted 20-Mar-2018; accepted I2-Jul-20I8

Corresponding Author:

Sayaka Itoh, MSc, Bio-Innovation Policy Unit, Department of Computational Biology and Medical Sciences, Graduate School of Frontier Sciences, University of Tokyo, Bioscience Bldg B-I7, 5-I-5, Kashiwanoha, Kashiwa City, Chiba, 8562, Japan.

Email: s.itoh@edu.k.u-tokyo.ac.jp 
how technology forecasting are or should be incorporated into the guidance formulation process. This may be because researchers have only focused on "general" technology forecasting such as the ones conducted periodically by NISTEP and not on the types of technology forecasting conducted for the specific purpose of regulation.

This calls for analyses on technology forecasting for the specific purpose of regulation. Though cases are scarce, technology forecasting are sometimes conducted by regulators themselves. Technology forecasting carried out by policy makers directly affects policies, and regulators' forecasting deeply influences regulations. ${ }^{11}$ Therefore, it is necessary to analyze the influence of past technology forecasting on guidance development and evaluate methods for utilizing technology forecasting for effective guidance development in the future.

As an example of a regulator-conducted technology forecast, the FDA performed decadal forecasts in 1998 and 2008, focusing on medical devices. ${ }^{12,13}$ In the 1998 forecast by the FDA, for example, they quantified the feasibility of multiple upcoming technologies, which were differentiated into "Generic Technology Areas" and "Specific Device Groups." They then discussed 6 major trend categories that comprise all product-type examples. Because these forecasts were carried out by the regulatory authorities themselves, the results of these forecasts are expected to have been reflected in the guidanceformulation process, providing guidance formulators with initial ideas regarding the type of guidance formulation that would be needed. Proof of such use of the FDA forecasting outcomes can be seen in a report issued after the 2008 forecast. ${ }^{14}$ In this report, forecasted technology trends are listed along with brief descriptions and views, including sentiments on regulatory needs or changes (eg, "CDRH will work to ensure that its regulatory science keeps pace with the increasing development and use of smart devices"), providing proof of technology forecasting being the first step to identifying regulatory challenges expected in the future. However, there is no additional evidence of the technology forecasting being used, particularly in the guidance-formulation process.

Another example of a regulator-conducted technology forecast is the "Health, Labour and Welfare Scientific Research Special Research Project," ${ }^{15}$ which was a collaborative forecast carried out by the Ministry of Health, Labour and Welfare (MHLW) and the Ministry of Economy, Trade and Industry (METI) of Japan in 2004. This forecast had been oriented from the beginning to prioritize technology themes that were in need of policy changes including guidance formulation. The perceived requisite guidance-formulation activities were then carried out under the "Guidance Projects for the Evaluation of Emerging Technology Medical Devices."16

Studies have assessed the realization of technology forecasting in general, ${ }^{17}$ and some researches have attempted to address approaches that allow for identification of fields for regulatory action to foresee regulatory changes based on technology forecasting. ${ }^{18}$ However, no researches have addressed the relationship between technology forecasting for regulation and the regulatory outcomes, or how the forecasts are utilized in the guidance-formulation process. The technology forecast carried out by MHLW, a rare case that has a visible connection to guidance formulation shortly after the forecasting, still lacks post facto analyses between the 2 activities.

\section{Methods for Analyzing Relationships Between Technology Forecasting and Guidances}

No successful models applicable to post facto assessments of medical technology forecasting and the link to guidances have been developed to date. The initial step to build a framework for analyzing forecast/guidance relationships is to think about the classification of both forecasted technologies and the resulting guidances. FDA's classification differed between the first and second forecasts, probably reflecting the technology trends at the time of the forecasts. ${ }^{12,13}$ The Sunagawa team's classification was different from FDA's. ${ }^{15}$ This indicates technology classification in forecasts is an issue and is not harmonized between countries or forecasts.

The Global Harmonization Task Force (GHTF) dedicated a report for risk classification of medical devices in order to realize global harmonization of medical device regulatory systems, indicating they had encountered difficulties in international harmonization under different technology classifications. ${ }^{19}$ Furthermore, technology classification plays a key role when regulators or the applicants for approval need to identify the definition and corresponding set of guidances intended for medical products, as found by the FDA's Device Classification Panel ${ }^{20}$; however, there is no direct mention of technology classification for the linkage between products and guidances. In 1999, Robert et al introduced a categorization for new health care technologies, according to the development stages of technologies deductible from the information sources, in which technologies were classified as primary (the manufacturer or innovator), secondary (knowledge or expertise intended for other purposes), and tertiary (other agencies' efforts to identify technologies). ${ }^{21}$ Text mining could be applied to technology forecasting results. However, technology forecasting results often do not provide informative notes to allow text mining, particularly when third parties use publicized information for investigations.

Rules have also been classified in a multitude of ways. For example, rules are classified as "general" and "specific" or simply allotted into categories such as "laws" and "guidances." Laws may be classified as public, private, or international laws. ${ }^{22}$ The effect of classified rules has also been reported (eg, the effects of "specific" and "general" rules on ethical decisions have been reported ${ }^{23}$ ), indicating that classification of rules may play an important role in analyzing past decisions or policy actions. However, there is no classification of guidances that aims to enable analysis between rules and technology forecasting. ${ }^{24,25}$ 


\section{Objectives}

This study was initiated to answer a simple question: How could regulatory authorities make better rules quicker for new technologies? Identifying and assessing emerging technologies ahead of time specifically for guidance formulation activities is one solution. However, there are no analytical frameworks that enable post facto analyses of the relationship between technology forecasting and formulated guidances; moreover, frameworks that allow inter-forecast or international comparisons. Accordingly, in this study, we aimed to examine the utilization of technology forecasting conducted specifically for guidance formulation by regulatory authorities in the medical field. We propose a framework that includes a classification criteria that would enable linkages between a set of technologies and the resulting set of guidances and then discuss the characteristics of the relationship, focusing on what kind of guidances regulatory authorities decide to formulate.

\section{Methods}

\section{Case Selection}

In order to conduct a study on the relationship between technology forecasting and guidances, the study case must fulfill the requirement that the technology forecasting activities and guidance formulation activities are connected and trackable. The MHLW and METI conducted a collaborative technology forecasting project for medical devices under an MHLW project (hereinafter, the Sunagawa team forecast) regarding new and upcoming medical devices in $2004 .{ }^{15}$ As the first step to identify the future technological direction, they examined surveys targeting a group of experts including clinicians, companies, and academic societies and were able to estimate the feasibility of 117 advanced medical technologies. The survey results were then scrutinized together with additional opinions from committee members to identify technology areas in need of policy, regulatory, or industrial actions, which resulted in 7 prioritized technology fields; DNA/RNA microarray, molecular imaging diagnosis, catheter surgery with ultrasonic imaging, surgery robot, bionic medical devices, artificial hearts, and regenerative medicine.

The guidance formulation activities were taken over by the Guidance Projects for the Evaluation of Emerging Technology Medical Devices, a double-track project carried out by MHLW and METI. ${ }^{15}$ MHLW and METI both set up working groups of their own and held individual and collaborative working group meetings. Though the working groups were established individually by both MHLW and METI, the concept of the project was cooperation of MHLW and METI; thus, working groups were set up in pairs, resulting in having the same or similar working group names. Guidances formulated by working groups under MHLW aimed to expedite the regulatory review of medical devices, whereas METI's working groups aimed to speed up and optimize the development and production

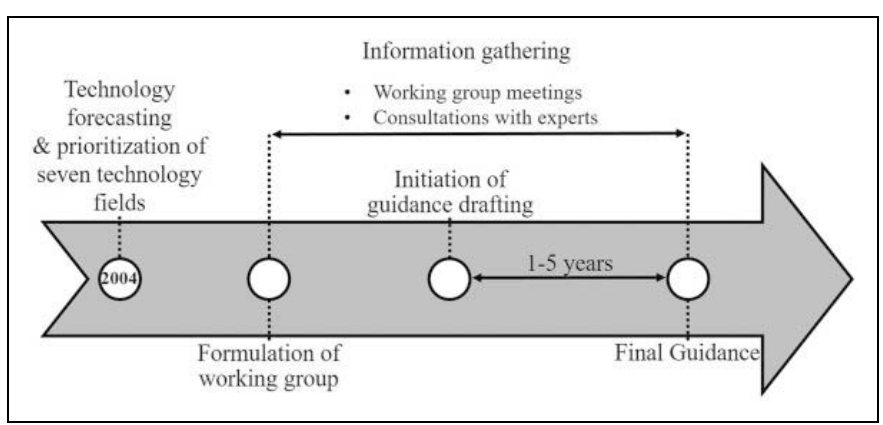

Figure I. Timeline of guidance formulation process. The guidance formulation process started off from technology forecasting and prioritization of technology fields. Working groups were formulated, and guidances were developed with regular working group meetings and information gathering by consultations with experts. Guidance are drafted over a period of time ranging from I to 5 years, after which the final guidance is released. The project for guidance formulation is still ongoing and new guidances are being developed; therefore, the timing of working group formulation, initiation of guidance drafting, and guidance release differs between guidances.

process. This double-track guidance formulation system and the resulting guidances were unique to Japan.

We identified 40 finalized guidances by the MHLW and METI working groups in the 10 years after the technology forecasting. Figure 1 shows the timeline of main events in the guidance formulation process in the Sunagawa team forecast and the Guidance Projects for the Evaluation of Emerging Technology Medical Devices. The sequential guidance formulation process makes this particular technology forecast an ideal sample to analyze the relationship between regulatorconducted technology forecasting and the guidance formulation outcome.

\section{SN-PA Classification}

All 117 technologies identified by the Sunagawa team were closely examined to detect overlapping technologies, which were integrated into a single technology. Technologies with no enlisted names or no evaluation of feasibility were removed from the technology list. Thus, a total of 108 technologies were analyzed. The feasibility of technologies had been assessed by the Sunagawa team according to when they were likely to be realized. Therefore, technologies that were thought to be realized the earliest were marked as "highly prioritized" technologies. The technologies were not specifically classified and were therefore a mixture of devices, diseases, disease sites, core technologies, and medical concepts. It was necessary to develop a new technology classification method because, to our knowledge, no technology classification fit the following criteria: (1) could cover all listed technologies in the technology forecast, (2) permitted observations of the relationship between the formulated guidances and forecasted emerging technologies, and (3) permitted future comparisons between different case studies or for international comparisons. 
Importantly, FDA provides a method for categorizing medical devices through their website to potential sponsors according to the disease or body part that the devices target or as selection keys for guidance categorization or classification to let the sponsors know what guidances they are obliged to follow. ${ }^{20}$ This indicates that regulatory authorities use a diseaseoriented designation of guidances as a way to match them with technologies.

This principle was the basis for the development of a new classification method, and the only method that would cover all 3 criteria would be to divide the technologies into 2 categories according to whether the technology names contained disease-related terms or not. Disease-related technologies have a specific disease or body part they are designed for and have a variety of core technologies that make up the device (eg, artificial heart, fracture balance support system [computer-controlled], bone strength diagnosis device). In contrast, disease-independent technologies have a higher versatility of use and are intended for multiple applicable diseases and/or body parts (eg, cell sheet engineering, gene analysis system, cell function analysis system).

We named the disease-related technologies as "Needs" technologies (N-technologies) and the disease-independent technologies as "Seeds" technologies (S-technologies). The 108 forecast technologies were divided into $\mathrm{N}$-technologies if the technology contained words related to diseases or body parts. Technologies were classified as S-technologies if they did not contain words related to diseases or body parts.

The 40 guidances issued during the ten years after the technology forecast were also classified into 2 categories according to whether the guidances were related to disease. This classification of guidances would allow observation (of the linkage) between technologies listed in the technology forecast and the formulated guidances. It would also cover every guidance formulated after the technology forecast and, being a simple form of classification, would likely be applicable to any guidance formulated in the future. Moreover, this classification would allow analysis of and between cases. The disease-independent guidances, applicable to multiple diseases and body parts, are guidances for a certain general purpose technology and were grouped as "Platform" guidances (P-guidances). The diseaserelated guidances, classified as "Application" guidances (A-guidances), are guidances that regulate specific applications and diseases. The 40 guidances were classified as A-guidances if their titles contained words describing the target disease or target body part; otherwise, they were classified as P-guidances.

The classification of both forecasted technologies and guidances is termed the Seeds/Needs-Platform/Application (SNPA) classification in this study.

\section{Analytical Framework for Technology Forecast/ Guidances Relationship}

Although The SN-PA classification coordinates an unclassified list of technologies and guidances, the many-to-many

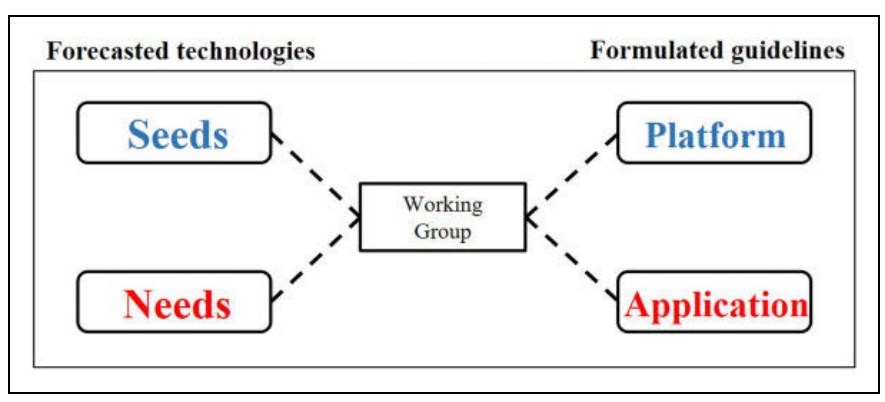

Figure 2. Framework for SN-PA pattern analysis.

relationship is still complex, and an intermediate group is needed to tie the 2 groups together. MHLW and METI started up working groups after the technology forecasting by the Sunagawa team. These working groups were established with the goal of discussing and formulating appropriate guidances for 7 prioritized technology fields identified by the technology forecasting; therefore, the names of the working groups were related to the corresponding 7 prioritized technology fields (DNA/RNA microarray, molecular imaging diagnosis, catheter surgery with ultrasonic imaging, surgery robot, bionic medical devices, artificial heart, and regenerative medicine).

Thus, the prioritized technology fields and working group names acted as intermediates between forecasted technologies and formulated guidances, therefore making it possible to form "forecasted technologies-prioritized technology fields working group-formulated guidances relationship" (T-W-G) bundles. These bundles provide a clear view of the relationship between multiple forecasted technologies and multiple formulated guidances. The 40 guidances were categorized according to their working group names, and the 108 forecasted technologies were then allotted into the categories.

The classification method above and analysis of the relationship between technology forecasting and guidances (which we will refer to as SN-PA pattern analysis; Figure 2) may facilitate 9 T-W-G patterns in total: Seeds-Application (S-A), Seeds-Platform (S-P), Needs-Application (N-A), SeedsApplication, Needs-Platform (N-P), Seeds/Needs-Platform (SN-P), Seeds/Needs-Application (SN-A), Seeds-Platform/ Application (S-PA), and Needs-Platform/Application (N-PA), Seeds/Needs-Platform/Application (SN-PA).

\section{Results}

A total of 108 candidate technologies were classified as either S-technologies or N-technologies, and the 40 guidances were classified as P-guidances or A-guidances. The forecasted technologies and resulting guidances were organized to allow further analysis of the relationship between technology forecasting and guidance formulation. Of the 108 technologies, a total of 20 technologies were discerned as being related to the 7 prioritized technology fields, which automatically linked to working groups and 31 guidances; a total of 8 T-W-G bundles were observed. 
Table I. The S-P Pattern.

\begin{tabular}{|c|c|c|c|}
\hline Forecasted Technologies & Prioritized Field & $\begin{array}{l}\text { Review WG Names } \\
\text { Formulated GL }\end{array}$ & $\begin{array}{l}\text { Development WG Names } \\
\text { Formulated GL }\end{array}$ \\
\hline $\begin{array}{l}\text { (S) Gene analysis system, cell } \\
\text { function analysis system } \\
\text { (S) Disease diagnosis system or } \\
\text { disease prevention system } \\
\text { based on genetic information }\end{array}$ & $\begin{array}{l}\text { DNA/RNA } \\
\text { microarray }\end{array}$ & $\begin{array}{l}\text { (P) Genotyping diagnostics } \\
\text { using DNA microarray } \\
\text { (P) Diagnostic devices based } \\
\text { on RNA profiling }\end{array}$ & $\begin{array}{l}\text { [WG] Tailor-made medical diagnostic devices (DNA } \\
\text { microarrays) } \\
\text { [WG] Tailor-made medical diagnostic devices (DNA } \\
\text { microarrays for gene expression analysis) } \\
\text { [WG] Tailor-made medical diagnostic devices } \\
\text { (Development guidances dissemination activities) } \\
\text { (P) DNA microarrays } \\
\text { (P) DNA microarrays for genotype (genotyping) assay } \\
\text { (P) DNA microarrays for gene expression analysis } \\
\text { (P) Technical Specification draft on DNA microarrays } \\
\text { for gene expression analysis }\end{array}$ \\
\hline $\begin{array}{l}\text { (S) } \star \text { Computer-aided diagnostic } \\
\text { device, Positron emission CT }\end{array}$ & $\begin{array}{l}\text { Molecular imaging } \\
\text { diagnosis }\end{array}$ & $\begin{array}{l}\text { [WG] Computer diagnosis } \\
\text { support device } \\
\text { (P) Computer diagnosis } \\
\text { support devices }\end{array}$ & $\begin{array}{l}\text { [WG] Diagnostic imaging (computer diagnosis support } \\
\text { devices) } \\
\text { (P) Software design and development management in } \\
\text { computer diagnosis support devices }\end{array}$ \\
\hline
\end{tabular}

(S), technologies classified as Seed-oriented; (P), platform guidances; WG, working group; GL, guidance; $\star$, high prioritization

Table 2. The N-A Pattern.

\begin{tabular}{|c|c|c|c|}
\hline Forecasted Technologies & $\begin{array}{l}\text { Prioritized } \\
\text { Field }\end{array}$ & $\begin{array}{l}\text { Review WG Names } \\
\text { Formulated GL }\end{array}$ & $\begin{array}{l}\text { Development WG Names } \\
\text { Formulated GL }\end{array}$ \\
\hline $\begin{array}{l}\text { (N) Artificial heart } \\
\text { (N) } \star \text { Next-generation implantable artificial heart system } \\
\text { (N) Compact, high-performance, fully self-contained } \\
\text { artificial heart (auxiliary artificial heart, and total artificial } \\
\text { heart) } \\
\text { (N) Artificial heart (Fully substituted total artificial heart) } \\
\text { (N) Artificial heart (compact heart suitable for Japanese), } \\
\text { robotics-aided surgery assisting device (for endoscopic } \\
\text { surgery), DDS such as cells for regenerative medicine } \\
\text { (N) Artificial heart, implantable cardioverter defibrillators }\end{array}$ & $\begin{array}{r}\text { Artificial } \\
\text { Heart }\end{array}$ & $\begin{array}{l}\text { [WG] Active Implantable } \\
\text { Devices (high-performance } \\
\text { artificial heart system) } \\
\text { (A) Next-generation artificial } \\
\text { heart }\end{array}$ & $\begin{array}{l}\text { [WG] Active Implantable } \\
\text { Devices (high-performance } \\
\text { artificial heart system) } \\
\text { (A) High-performance artificial } \\
\text { heart systems }\end{array}$ \\
\hline (N) Implantable bionic treatment devices & $\begin{array}{l}\text { Bionic medical } \\
\text { devices }\end{array}$ & $\begin{array}{l}\text { [WG] Neuromodulation } \\
\text { (A) Nerve function repair } \\
\text { devices }\end{array}$ & $\begin{array}{l}\text { [WG] Bionic medical devices } \\
\text { (nerve stimulation devices) } \\
\text { (A) Implantable nerve } \\
\text { stimulation devices }\end{array}$ \\
\hline
\end{tabular}

$(N)$, technologies classified as Need-oriented; (A), application guidances; WG, working group; GL, guidance; $\star$, high prioritization

Four patterns were identified as routes taken from technology forecasting to guidance formulation. These patterns indicated how the profile of a technology (being related to diseases or not) was recognized by the guidance formulators as technology versatility, leading to the formulation of guidances that either focused on a general technology and covered a broader range of applications or focused on a specific application and provided directions for a variety of general technologies associated with the specific application. The characteristics of each of the 4 patterns and speculations of the remaining 5 patterns are discussed below.

\section{S-P Pattern}

The development of P-guidances initiated from diseaseindependent technologies is represented by prioritized technology fields such as DNA/RNA microarray analysis and molecular imaging diagnosis, which combine seeds-oriented technologies such as gene analysis system and cell function analysis system (Table 1). The S-P pattern is observed under conditions in which the forecasted technology is diseaseindependent and P-guidances are thought to be necessary.

\section{N-A Pattern}

The N-A pattern can be observed when guidance formulators encounter a group of disease-related forecasted technologies and recognize the necessity to make individual guidances for each application. In our study case, prioritized technology fields showing N-A pattern was bionic medical devices and artificial heart (Table 2). 
Table 3. The S-A Pattern.

\begin{tabular}{|c|c|c|c|c|}
\hline Forecasted Technologies & Prioritized Field & $\begin{array}{l}\text { Review WG Names } \\
\text { Formulated GL }\end{array}$ & \multicolumn{2}{|c|}{$\begin{array}{c}\text { Development WG Names } \\
\text { Formulated GL }\end{array}$} \\
\hline $\begin{array}{l}(\mathrm{S}) \star \text { Surgical equipment, } \\
\text { biomaterials }\end{array}$ & $\begin{array}{l}\text { Catheter surgery with } \\
\text { ultrasonic imaging }\end{array}$ & $\begin{array}{l}\text { [WG] Critical limb ischemia } \\
\text { (A) Medical devices for critical limb ischemia disease treatment }\end{array}$ & - & - \\
\hline
\end{tabular}

(S), technologies classified as Seed-oriented; (A), Application guidances; GL, guidance; WG, working group; $\star$, high prioritization

Table 4. The SN-PA Pattern.

\begin{tabular}{|c|c|c|c|}
\hline Forecasted Technologies & $\begin{array}{l}\text { Prioritized } \\
\text { Field }\end{array}$ & $\begin{array}{l}\text { Review WG Names } \\
\text { Formulated GL }\end{array}$ & $\begin{array}{l}\text { Development WG Names } \\
\text { Formulated GL }\end{array}$ \\
\hline $\begin{array}{l}\text { (S) } \star \text { Cell sheet engineering } \\
(\mathrm{N}) \star \text { Tissue-engineered products such } \\
\text { as cultured bone and cartilage }\end{array}$ & $\begin{array}{l}\text { Regenerative } \\
\text { medicine }\end{array}$ & $\begin{array}{l}\text { [WG] Cell sheet } \\
\text { (A) Cell sheet for treating severe heart } \\
\text { failure } \\
\text { (A) Corneal epithelial cell sheet } \\
\text { (A) Corneal endothelial cell sheet } \\
\text { (A) Articular cartilage regeneration } \\
\text { (A) Cell sheet for periodontal tissue } \\
\text { treatment } \\
\text { (A) Autologous iPS cell-derived retinal } \\
\text { pigment epithelial cell }\end{array}$ & $\begin{array}{l}\text { [WG] Myocardial sheet } \\
\text { [WG] Efficacy evaluation technology for } \\
\text { tissue (cartilage) regeneration } \\
\text { (P) Designing human cell culture processing } \\
\text { equipment } \\
\text { (P) Decontamination path box designs } \\
\text { (P) Sterile connection interface designs } \\
\text { (P) Transport of human cells and tissues } \\
\text { during research and development of cell/ } \\
\text { tissue-processed products }\end{array}$ \\
\hline $\begin{array}{l}\text { (S) } \star \text { Next-generation surgery with MR } \\
\text { images, robots, new materials, and } \\
\text { bio-imaging } \\
\text { (N) Fracture balance support system } \\
\text { (computer-controlled), bone } \\
\text { strength diagnosis device }\end{array}$ & & (A) Joint surgery support devices & $\begin{array}{l}\text { (P) Quality assurance of positioning } \\
\text { performance of navigational medical } \\
\text { devices } \\
\text { (A) Fracture reduction support systems } \\
\text { (A) Brain tumor ablation laser scan systems }\end{array}$ \\
\hline $\begin{array}{l}\text { (S) } \star \text { Machinery and equipment } \\
\text { essential for minimally invasive } \\
\text { surgery with safety and reliability }\end{array}$ & Surgery robot & $\begin{array}{l}\text { [WG] Navigated surgery (surgical } \\
\text { robot) } \\
\text { Second sector (targeting soft tissues) }\end{array}$ & [WG] Navigated surgery (surgical robot) \\
\hline $\begin{array}{l}\text { (S) } \star \text { Surgery support/assist robots } \\
\text { (N) Real-time visualization and } \\
\text { navigation system for intracardiac } \\
\text { electrical excitation propagation }\end{array}$ & & $\begin{array}{l}\text { (A) Computer-aided surgical devices } \\
\text { for soft tissues }\end{array}$ & (P) Navigation medical field intersection \\
\hline
\end{tabular}

(S), technologies classified as Seed-oriented; (N), technologies classified as Need-oriented; GL, guidance; (P), Platform guidances; (A), Application guidances; WG, working group; $\star$, high prioritization

\section{S-A Pattern}

The S-A pattern is a unique pattern that is not consistent with the general reasoning that a disease-related technology would initiate the formulation of an A-guidance or that diseaseindependent technologies would lead to P-guidances. Our case study showed that surgical equipment and biological materials, which was prioritized as catheter surgery with ultrasonic imaging, assumed the S-A pattern (Table 3).

\section{SN-PA Pattern}

In cases in which guidance formulators encounter a group of related forecasted technologies containing both disease-related and disease-independent technologies, both P-guidances and A-guidances were formulated, thus forming a guidance formulation pattern of SN-PA (Table 4). Our case study showed that prioritized technology fields such as regenerative medicine and surgical robots formed an SN-PA pattern.

\section{Discussion}

The 4 patterns that were observed in the results and the implications obtained from the results and the tacit recognition of forecasted technologies by regulatory authorities in the advanced medical field is discussed below. 


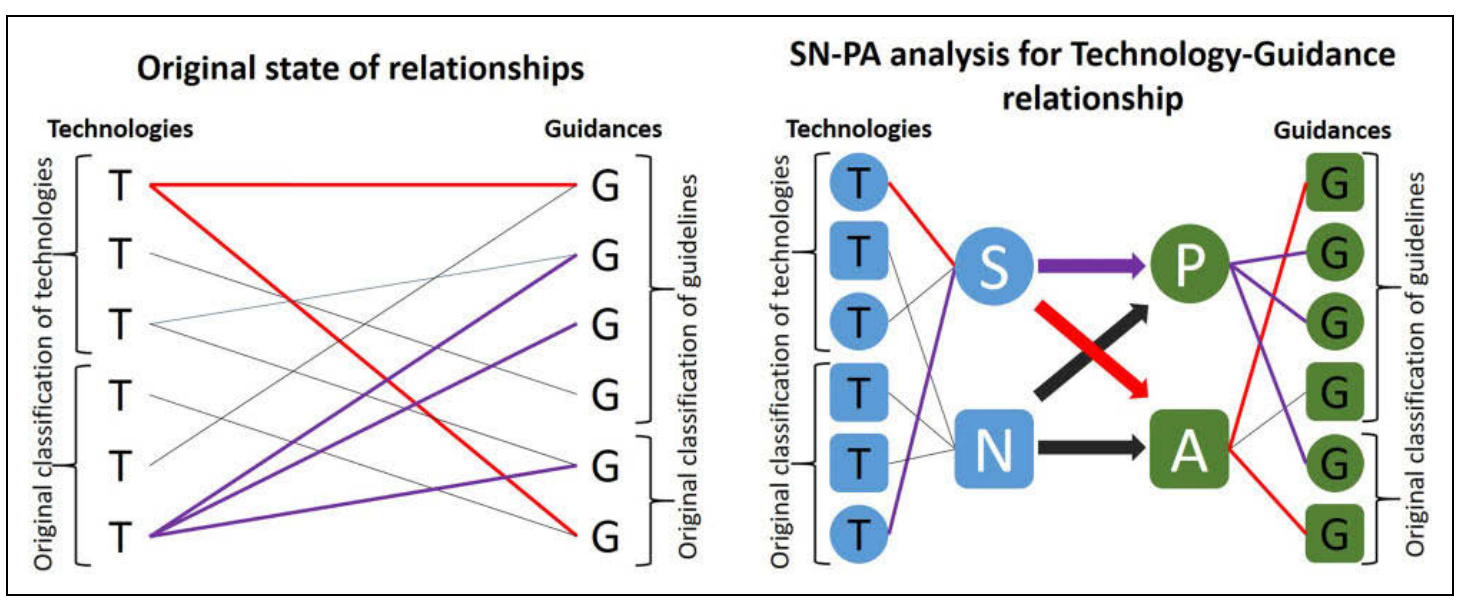

Figure 3. Function of SN-PA analysis for technology-guidance relationship. The left image displays the original state of relationships where technology-guidance relationships are difficult to comprehend. The right image displays how the SN-PA framework facilitates the analysis of technology-guidance relationships. An example of the S-A pattern is shown in red, and an example of the S-P pattern is shown in purple.

\section{Reasons of the 4 Patterns}

The basic and obvious patterns are the S-P and N-A patterns. As observed in our case study, 4 of the 7 T-W-G relationships followed either the S-P or the N-A pattern. To further our understanding of these 2 patterns, we examined the guidance contents.

We found that the N-A pattern was characteristic of technologies already in existence but with the actual products still emerging. For example, technologies related to artificial hearts have been used worldwide for decades; thus, many international and national standards and guidances have been established. The 2 guidances of the N-A pattern referenced pre-existing international standards, national standards and guidances. ${ }^{26,27}$ The guidances' description of its purpose and scope indicate that those guidances are intended for a certain disease (diseases related to the heart in this example) and cover a range of technologies associated with the intended medical device. Guidances of the S-P pattern have a distinct description of its purpose and scope that the guidances are intended for general purpose medical technologies, which target a variety of diseases. ${ }^{28}$

The S-A pattern is an exceptional pattern that does not follow general reasoning that a disease-related technology would initiate the formulation of an A-guidance or that disease-independent technologies lead to P-guidances, as do the 2 aforementioned patterns. In the S-A patterns, there would be a need to discuss, detect, and add a disease-related subject not listed in the technology forecast, but which would still require guidance formulation in order to solve medical needs. In cases such as the "surgical equipment and biomaterials," which is a broad categorization for a variety of seed technologies, regulators would have found it difficult to find the focus on seed technologies. This would have lead them to find the need for regulation by searching for more specific technologies or applications. The guidance formulated in the case of "surgical equipment and biomaterial" was the guidance for critical limb ischemia. Critical limb ischemia was not included in the technology forecast, and is therefore a "needs" picked up by the regulators after the technology forecasting. This implicates that there are certain tacit applications that are strongly connected with the S-technologies.

Next we investigated the guidance documents of the SN-PA pattern and found that the guidances had fewer references of standards or guidances developed in other countries than the other patterns. ${ }^{29}$ The guidances and accounts of working group meetings highlighted the importance of the regenerative medicine field, both in economical and medical welfare, and reflected the need for changes in the more upper regulatory frameworks, such as the Pharmaceutical Affairs Laws. ${ }^{30}$ This indicated that the SN-PA pattern may be typical for cuttingedge technologies with the surrounding rules (including guidances) in need of renewal or formulation, which would call for both A-guidances and P-guidances in order to improve the reviewing process. The description of the purpose of the guidances indicate that the guidances are intended for either a disease or a general purpose medical technology, implying that the SN-PA pattern is composed of N-A and S-P patterns.

\section{Implications}

The results of this study have 2 implications. First, the classification methods we proposed in this study may be utilized as a basis for discussing classification systems of technologies and guidances. The fact that technologies, technology forecasting methods, and the preference of classification methods differ between nations makes it difficult to establish an internationally shared classification system that would enable regulatory authorities, innovators, and third parties to perform comparisons and analyses of the relationships between technology forecasting and guidance formulation.

Therefore, the classification of technologies and guidances presented in this study, though it may seem primitive, is of importance. Figure 3 displays how the simple dichotomization 
of technologies and guidelines we proposed in this study would allow medical device regulatory authorities, innovators, and third parties to reclassify any technologies regardless of technology forecast methods or what classification criteria is originally adopted in the technology forecast.

The second implication is that the regulatory authorities follow certain patterns from technology forecasting to guidance formulation when certain classification is applied to technologies and guidances, indicating that technology forecasting based on our SN-PA framework may improve the understanding of subsequent regulatory activities.

Therefore, from the regulator's point of view, when guidance formulators encounter highly prioritized technologies in need of new guidances, utilizing the SN-PA framework may help them identify what sort of guidances they should formulate, thereby contributing to deciding the "missions" of the guidance formulators. Our case study suggests that guidance formulators may need to formulate: only A-guidances, or both P-guidances and A-guidances for disease-related technologies; and only P-guidances, only A-guidances, or both P-guidances and A-guidances for disease-independent technologies. From the point of view of innovators, the SN-PA framework may assist the communication with regulators before guidance drafting.

From another perspective, this study may be of interest to technology forecasters. The fact that there have been technology forecasting conducted by regulators in the past indicates that collaborative or commissioned forecasts for specific purposes such as surveillance for regulation needs may be accommodating to users concerned in the specific field or purpose. In such cases, frameworks such as the SN-PA framework that reprocess medical technologies and guidance to allow the observation or the relationship or to point out future directions for guidance formulation may prove to be of use.

\section{Conclusions}

The key concept of this study was the dichotomization of technologies and guidances, which allowed the patterning of the relationship. By selecting a congruent case, we found that the activities of regulatory authorities who recognized technologies identified via technology forecasting could be grouped into 4 specific SN-PA patterns. The patterning explicated "what kind of guidances are formulated for which kind of technologies." The 4 patterns provide evidence with actual examples for analyzing the relationship between technology forecasting for regulation and guidance formulation during the guidanceformulation process in order to allow observation of the utilization of technology forecasting by regulatory authorities.

\section{Authors' Note}

The concept of the research was presented at 2014 Japan MOT society, which was held at the University of Tokyo on March 14, 2015.

\section{Declaration of Conflicting Interests}

No potential conflicts were declared.

\section{Funding}

Both authors report a grant from Research Institute of Science and Technology for Society (RISTEX) of Japan Science and Technology Agency (JST) during the conduct of the study, and a grant from Japan Association for the Advancement of Medical Equipment (JAAME), outside the submitted work.

\section{ORCID iD}

Sayaka Itoh, MSc (D) https://orcid.org/0000-0001-7244-0839

\section{References}

1. Deloitte. 2016 Global life sciences outlook: moving forward with cautious optimism. 2016.

2. Hamburg MA.Shattuck lecture. Innovation, regulation, and the FDA. N Engl J Med. 2010;363(23):2228-2232.

3. FDA. Innovation or stagnation? Challenge and opportunity on the critical path to new medical products. Department of Health and Human Services; US Food and Drug Administration, Center for Biologics Evaluation and Research, 2004.

4. Advancing regulatory science for public health - a framework for FDA's regulatory science initiative. Department of Health and Human Services; US Food and Drug Administration, Office of the Commissioner; Office of the Chief Scientist, 2010.

5. European Medicines Agency. Advanced therapies-guidances relevant for advanced-therapy medicinal products. http://www. ema.europa.eu/ema/index.jsp?curl=pages/regulation/general/ general_content_000298.jsp\&mid=WC0b01ac05800862bd. Accessed December 21, 2015.

6. Anderson J. Technology foresight for competitive advantage. Long Range Plann. 1997;30(5):665-677.

7. Warnke P, Heimeriks G. Technology Foresight as Innovation Policy Instrument: Learning from Science and Technology Studies. Berlin: Springer, 2008.

8. Science and Technology Foresight Center, National Institute of Science and Technology Policy (NISTEP). The 9th Science and Technology Foresight - Contribution of Science and Technology to Future Society. 2010. http://data.nistep.go.jp/dspace/bitstream/ 11035/693/3/NISTEP-NR140-SummaryE.pdf.

9. Science and Technology Foresight Center, National Institute of Science and Technology Policy (NISTEP). The 10th Science and Technology Foresight: Future Perspectives on Science and Technology by Field. 2015. http://data.nistep.go.jp/dspace/handle/ $11035 / 3080$.

10. Wild C, Langer T. Emerging health technologies: informing and supporting health policy early. Health Policy 2008;87(2): 160-171.

11. Blind K. New Products and Services: Analysis of Regulations Shaping New Markets: Final Report. European Commission, Directorate-General for Enterprise; Fraunhofer Institute for Systems and Innovation Research. Luxembourg: EUR-OP, 2004. 
12. Herman WA, Marlowe DE, Rudolph H. Future trends in medical device technology: results of an expert survey. 1998. www.fda. gov/cdrh/ost/trends/toc.html. Accessed September 25, 2008.

13. Herman W, Devey G. Future trends in medical device technologies. 2008.

14. Regulatory science in FDA's Center for Devices and Radiological Health: a vital framework for protecting and promoting public health. www.fda.gov/downloads/AboutFDA/CentersOffices/Offi ceofMedicalProductsandTobacco/CDRH/CDRHReports/ UCM274162.pdf. Accessed June 6, 2017.

15. Sunagawa Team (MHLW), and Prioritization Committee for Next Generation of Medical Device (METI). Tentative prioritization results of future medical device [in Japanese]. http://www. jfmda.gr.jp/metis/002/pdf/02_02_01.pdf.

16. Medical Engineering Technology Industrial Strategy Consortium (METIS). Medical Device Regulatory Science Guidebook. 2012. http://www.jfmda.gr.jp/metis/guidebook/pdf/120801/120801_01. pdf. Accessed December 30, 2015.

17. Yokoo Y. Does sciences \& technologies forecasted in past forecast survey are realized [in Japanese]? Sci Technol Trends. 2010; $23-32$.

18. Blind K. Regulatory foresight: methodologies and selected applications. Technol Forecast Soc Chang. 2008;75:496-516.

19. The Global Harmonization Task Force. Principles of medical devices classification. GHTF/SG1/N15, 2006. http://www.imdrf. org/docs/ghtf/final/sg1/technical-docs/ghtf-sg1-n15-2006-gui dance-classification-060627.pdf (accessed June 10, 2016).

20. US Food and Drug Administration. Classify your medical device - device classification panels. http://www.fda.gov/MedicalDe vices/DeviceRegulationandGuidance/Overview/ClassifyYourDe vice/ucm051530.htm. Accessed December 30, 2015.
21. Robert G, Stevens A, Gabbay J. "Early warning systems" for identifying new healthcare technologies. Health Technol Assess. 1999;3(13):1-108.

22. Pound R. Classification of law. Harv Law Rev. 1924;37(8):933.

23. Mulder LB, Jordan J, Rink F. The effect of specific and general rules on ethical decisions. Organ Behav Hum Decis Process. 2015;126:115-129.

24. Mahoney PG, Sanchirico CW. General and specific legal rules. $J$ Institutional Theor Econ. 2005;161(2).

25. Engel C. General and specific rules: comment. $J$ Institutional Theor Econ. 22nd International Seminar on the New Institutional Economics Game Theory and the Law, vol. 161, no. 2, 2005.

26. Next generation artificial heart. PFSB/ELD/OMDE (Yakushokuki) Notification no. 0404002, 2008. http://dmd.nihs.go.jp/jise dai/tsuuchi/H20.4.4薬食機040402.pdf. Accessed June 16, 2017.

27. Nerve function repair devices. PFSB/ELD/OMDE (Yakushokuki) Notification 1215 no. 1, 2010. http://dmd.nihs.go.jp/jisedai/tsuu chi/H22.12.15薬食機1215第1.pdf. Accessed June 16, 2017.

28. Genotyping diagnostics using DNA microarray. PFSB/ELD/ OMDE (Yakushokuki) Notification no. 0404002, 2008. http:// dmd.nihs.go.jp/jisedai/tsuuchi/H20.4.4薬食機040402.pdf. Accessed June 16, 2017.

29. Articular cartilage regeneration. PFSB/ELD/OMDE (Yakushokuki) Notification 1215 no. 1, 2010. http://dmd.nihs.go.jp/jise dai/tsuuchi/H22.12.15薬食機1215第1.pdf. Accessed June 16, 2017.

30. Guidance projects for the evaluation of emerging technology medical devices, regenerative medicine products evaluation, regenerative medicine review working group 2009 report. Regenerative Medicine Review Working Group. http://dmd.nihs.go.jp/ jisedai/saisei/H27_saisei.pdf. Accessed June 16, 2017. 